\title{
Analysis of clinical parameters, drug consumption and use of health re- sources in a Southern European population with alcohol abuse disorder during COVID-19 pandemic.
}

\author{
Ana Lear-Claveras1, Beatriz González Álvarez², Sabela Couso-Viana ${ }^{3}$, Ana Clavería ${ }^{3,4,5 *}$ and Bárbara Oliván- \\ Blazquez ${ }^{1,5,6}$.
}

1 Aragonese Research Group in Primary Care (Grupo Aragonés de Investigación en Atención Primaria/GAIAP); Aragon Health Research Institute, Zaragoza, Spain.

2 Aragon Health Research Institute, Zaragoza, Spain.

3 I-Saúde Group, South Galicia Health Research Institute, Vigo, Spain.

4 Vigo Health Area, SERGAS, Vigo, Spain.

5 Primary Care Prevention and Health Promotion Research Network, RedIAPP, Madrid, Spain.

6 Department of Psychology and Sociology, University of Zaragoza, Zaragoza, Spain.

* Correspondence: anaclaveriaf@gmail.com

\begin{abstract}
The disruption in healthcare attention to people with alcohol dependence, along with psychological decompensation consequence of lockdown derived from COVID-19 pandemic, could have a negative impact on people who suffers from alcohol abuse disorder. Retrospective observational study of 9,966 men aged $>16$ years registered as having diagnosis of alcohol abuse disorder in the electronic medical records (EMR) of the Aragon Regional Health Service (Spain). Of those who were not infected during the study period (9,576), clinical (Glutamate-oxaloacetate -GOT-, Glutamate pyruvate -GPT-, creatinine, glomerular filtration, systolic blood pressure -SBP-, diastolic blood pressure -DBP-, total cholesterol, LDL, HDL, triglycerides, and body mass index -BMI-), pharmacological (dose per inhabitant per day -DHD- of drugs used in addictive disorders, benzodiazepines and antidepressants) and health resource use variables (primary and specialized care) were considered. Student's T-test for matched samples was performed. After carrying out the Levene's test, the Student's T-test was used to analyze the changes in clinical variables between alcohol abuse disorder patients with and without COVID-19. Only creatinine and LDL show a significant but clinically irrelevant changes just after and 6 months after the end of strict lockdown. The total number of DHDs for all drugs included in the study (except for Benzodiazepines), decreased. In the same way, the use of health services by these patients also decreased. The impact of COVID-19 among this group of patients has been moderate. The reorganization of health and social services after the declaration of the state of alarm in our country, made possible the maintenance of care for this vulnerable patients.
\end{abstract}

Keywords: COVID-19; alcohol use disorder; lockdown; primary care; lifestyle; health resources.

\section{Introduction}

COVID-19 stemming from the SARS-CoV-2 outbreak caused an unprecedented public health crisis around the world [1]. The declaration of the coronavirus disease as a pandemic in March 2020, and its dramatic development exposed the world population [2], especially at the beginning of the pandemic, to stressful situations [3]. In an effort to contain the spread of the new virus, the governments of many countries established restrictive measures based on limiting mobility. In the case of Spain, the government declared a state of national alarm on March 15, 2020, forcing citizens to confine themselves to their homes until May 3 [4]. These measures, which were useful to slow the spread of the virus, seem to have had a significant impact on the physical and mental health of the population [5]. 
Although many studies have shown an increase in the levels of stress, anxiety and depression during the months of lockdown among the general population [6-11]; few studies have evaluated the effect of this pandemic and the consequent lockdown on alcohol consumption patterns, despite the fact that the consumption of this substance could have been used to reduce the intensity of negative feelings caused by home lockdown [12].

It is estimated that in the world there are 237 million men and 46 million women who suffer from alcohol use disorder. In 2016, the harmful use of this substance caused more than 3 million deaths worldwide (three-quarters of these, in men); representing $5 \%$ of the global burden of disease [13]. Globally, that same year, alcohol consumption was the seventh risk factor for premature death and disability, and the main risk factor among the population aged 15 to 49 years [14]. Among young men in this age group, alcohol abuse is also the leading cause of disability in our country [15].

Studies on the impact of the pandemic and lockdown, on the consumption patterns of this substance in the general population, show variability in their results. Some studies report a decrease in consumption during the months of lockdown [16,17], while others studies report an increase in its consumption [18,19]. Those who increased their alcohol intake during lockdown experienced higher levels of stress, anxiety or depression than who maintained their habitual consumption or reduced it $[16,18,20,21]$; likewise, this increase was associated more frequently with individuals who declared themselves addicted to alcohol before the pandemic [17]. Some studies suggested that the psychological decompensation resulting from lockdown away from a socio-affective network could cause an increase in alcohol consumption and in the number of relapses among those who had alcohol consumption disorders before the pandemic [22-24].

Before the pandemic Primary Care (PC) services attended most of the demands related to alcohol problems, therefore, a significant number of visits in these centers were motivated by this problem and by the pathologies related to its consumption [15]. The pandemic forced, especially at the beginning, to modify the functions of the PC teams, among which were: detection and early diagnosis of alcoholism, performance of motivational interventions and referral to specialized treatment centers.

Changes in daily routines and the interruptions of care services for people with alcohol abuse disorder could have a particularly negative impact on the health status of this group [13,22]. Without a structured routine of non-alcohol related activities and without behavioral therapies, people with alcohol abuse disorders could more easily succumb to drinking during lockdown [22].

This increase in alcohol consumption during the pandemic could in turn worsen their health. Enough evidence has shown the existence of a dose-dependent effect between chronic alcohol consumption and viral infections (hepatitis C, HIV); thus, people with alcohol abuse disorders could have a higher risk of contracting COVID-19 [25]. Among this group, consumption of other substances (tobacco and other drugs) [26,27] and comorbidity with chronic (cancer, cardiovascular disease, liver disease, pancreatitis or diabetes) [28] and psychiatric pathologies (depression, disorder of generalized anxiety or bipolar disorder) is frequent [29], which could make them especially susceptible to a worse prognosis of infection [30].

Due to the lack of studies on the impact of the pandemic and lockdown in the population with alcohol dependence, the aim of this study is to analyze the changes in the clinical parameters, the consumption of drugs for the treatment of this addiction and the use of health resources, between the 6 months before the start of the lockdown and the 6 months after its end, in men diagnosed with alcohol abuse disorder in an autonomous community in northern Spain who did not contract COVID-19 infection during the study months; also comparing the variations in clinical parameters between uninfected alcoholic patients and those who were infected by the new virus.

\section{Materials and Methods}




\subsection{Design and study population}

Retrospective observational study of men over 16 years of age in the Autonomous Community of Aragon (Spain), diagnosed with alcohol abuse disorder in their electronic medical record (EMR) according to the criteria of the International Classification of Primary Care (ICPC-2): code P15 [31]. This disorder characterized by the loss of control over drinking, cause in the individual the compulsion to drink alcohol continuously or periodically in order to experience psychic effects or avoid the discomfort caused by its absence [32]. In order to know how the pandemic modified the clinical parameters and the use of drugs and health resources in these patients, only individuals with alcohol abuse disorder who did not contract COVID-19 during the months of studies were included.

From the EMR, information was collected for each individual in the 6 months prior to the start of the lockdown (09/14/2019 - 03/15/2020) and in the 6 months after its end $(05 / 03 / 2020-04 / 11 / 2020)$. The records collected during the months of strict lockdown were not considered, because these were very scarce.

Finally, also was valued the differences in clinical parameters in the 6 months prior to the start of lockdown and in the 6 months after its end, among individuals with a diagnosis of alcohol abuse who did not contract COVID-19 during the period of study and those who contracted the infection.

\subsection{Data sources}

This study is based on data from the electronic medical record of the PC services of Aragon.

The EMR completed its implementation throughout the Aragon health system in 2011. This record, shared by all the professionals that are part of the health system, pick up the data generated throughout the care process (PC and hospital care) by the patients covered by the National Health System.

\subsection{Variables}

The sociodemographic variables included in this study were: sex, age, pharmaceutical service and basic health area. The number of deaths among the population under study for each of the measurement periods was also collected; as well as chronic comorbidities with prevalences greater than 5\% [33] (arrhythmias, heart failure, ischemic heart disease, hypertension, dyslipidemia, obesity, overweight, disease in veins and arteries, cerebrovascular disease, diabetes, chronic bronchitis, COPD, asthma, disease kidney, hypo and hyperthyroidism, smoking, insomnia, chronic anxiety and depression, attempted suicide, anemia, neoplasia, dementia, hearing loss, cataracts, osteoarthritis, osteoporosis and dorsopathy).

Regarding the clinical and analytical parameters related to chronic alcohol consumption, the following were included: glutamic oxaloacetic transaminase (GOT), glutamic pyruvic transaminase (GPT), blood creatinine, glomerular filtration, systolic (SBP) and diastolic blood pressure (DBP), total cholesterol, low-density lipoprotein (LDL), high-density lipoprotein (HDL), triglycerides, and body mass index (BMI).

Changes in pharmacological treatment were assessed through variations in the total number of defined daily doses per 1,000 inhabitants per day (DHD) dispensed in the pharmacy. DHDs were calculated from the defined daily dose (DDD) stipulated by the World Health Organization (WHO), according to the following formula:

$$
D H D=\frac{\text { Registered consumption of the active ingredient } * 1000 \text { inhabitants }}{\text { Standard DDD } * n^{-} \text {inhabitants } / \text { period } * 365 \text { days }}
$$

Taking into account the Anatomical, Therapeutic, Chemical (ATC) classification system, the codes of the drugs of choice for the treatment of this pathology were analyzed according to the Spanish Society of Family and Community Medicine (Sociedad Española 
de Medicina de Familia y Comunitaria - semFYC) [34]: N07 (drugs used in additive disorders), N05 (benzodiazepines) and N06 (antidepressants).

Lastly, the use of health resources by these patients was assessed with the use of PC services (number of ordinary or continuous care visits at the health center or at home by the nurse or the general practitioner, and number of visits to other professionals in the health center: social workers) and with the use of hospital services (number of visits in outpatient care, number of diagnostic tests performed, number of visits to the emergency service, and number of hospitalizations) for each of the periods.

\subsection{Statistical analysis}

The sample size allowed the use of parametric methods [35]. In order to know the sociodemographic characteristics and the most frequent chronic comorbidities among the study population, a descriptive analysis was carried out using frequencies, means and standard deviation.

For the clinical variables, the mean and standard deviation (SD) of each parameter at each of the study moments (6 months before the start of lockdown, first measurement after the end of lockdown and 6 months later) was calculated. If for the same individual there was more than one measurement for the same parameter, the mean and interquartile range (IQR) were calculated. To compare the differences in means in the clinical parameters of chronic drinkers between the measurement before the start of lockdown and the first measurement after its ends, and between the previous measurement and the measurement at 6 months, the Student's T-test for paired samples was used.

Differences in drug consumption were assessed through the DHDs dispensed in the pharmacy to the study population in each of the periods. To determine the variations in the use of healthcare resources, the Student's T-test for paired samples was also used.

After carrying out the Levene tests of homogeneity of variances, the Student's T-test was used to compare the changes in clinical parameters between alcohol abuse disorders patients infected with COVID-19 and with those who did not contract the infection.

\subsection{Ethical considerations}

This work was carried out under the principles of the Declaration of Helsinki and complies with the ethical standards of the Aragón Clinical Research Ethics Committee (study protocol PI20 - 175).

The Aragonese Health Service provided the medical records of the patients included in the study. The treatment, communication and transfer of these personal data, was adjusted to the provisions of Regulation (EU) 2016/679 of the European Parliament and Organic Law on Protection of Personal Data and guarantee of digital rights 03/2018.

\section{Results}

Six months before the start of the lockdown, 9,966 men over 16 years of age in Aragon had a diagnosis of alcohol abuse in their EMR. 9,576 (96.1\%) did not become infected with COVID-19 during the study months, 390 (3.9\%), however, presented the infection during the same period of time. Of these, 39 cases were declared during the months of lockdown and 351 in the 6 months after its end. Regarding the number of deaths, 3 people died in the months prior to the declaration of the state of alarm, 41 during lockdown and 145 in the following 6 months.

Among those who did not contract the infection during the study period, the mean age of the sample was 56.4 (12.9). Almost two thirds (71.3\%) had an income of less than 18,000 euros per year and more than half (51\%) lived in urban areas with more than 10,000 inhabitants. Among the male population with chronic alcohol consumption who was not infected with the new virus, the most frequent chronic comorbidities were: dyslipidemia $(46.1 \%)$, followed by smoking (44.3\%), hypertension $(36.9 \%)$ and anxiety and depression (30.4\%) [Table 1]. 
Table 1. Sociodemographic data and chronic comorbidities in alcohol abuse disorder patients from Aragon.

\begin{tabular}{|c|c|c|}
\hline & & $\mathrm{N}(\%)$ \\
\hline Age & Mean (SD) & $56.4(12.9)$ \\
\hline \multicolumn{3}{|c|}{ Pharmaceutical service } \\
\hline & $<18000$ & $6824(71,3)$ \\
\hline & Between 18000 - 100000 & $2007(21.0)$ \\
\hline & $>100000$ & $19(0.2)$ \\
\hline & Free pharmacy & $696(7.3)$ \\
\hline & Mutualist & $26(0.3)$ \\
\hline & Uninsured & $4(0.0)$ \\
\hline
\end{tabular}

Basic health area

Urban

$5279(55.1)$

Rural

4297 (44.9)

Chronic comorbidities (Yes \%)

$\begin{array}{lr}\text { Arrhythmias } & 519(5.4) \\ \text { Heart failure } & 195(2.0) \\ \text { Ischemic heart disease } & 532(5.6) \\ \text { Hypertension } & 3534(36.9) \\ \text { Dyslipidemia } & 4418(46.1) \\ \text { Obesity } & 1327(13.9) \\ \text { Overweight } & 160(1.7) \\ \text { Disease in veins/arteries } & 505(5.3) \\ \text { Cerebrovascular disease } & 464(4.8) \\ \text { Diabetes } & 1584(16.5) \\ \text { Chronic bronchitis } & 182(1.9) \\ \text { COPD } & 1009(10.5) \\ \text { Asthma } & 356(3.7) \\ \text { Chronic kidney disease } & 337(3.5) \\ \text { Hypothyroidism } & 350(3.7) \\ \text { Hyperthyroidism } & 117(1.2) \\ \text { Smoking } & 4241(44.3) \\ \text { Insomnia } & 1377(14.4) \\ \text { Anxiety and depression } & 2910(30.4) \\ \text { Autolytic attempt } & 149(1.6) \\ \text { Anemia } & 947(9.9) \\ \text { Neoplasia } & 2015(21.0) \\ \text { Dementia } & 140(1.5) \\ \text { Hearing loss } & 763(8.0) \\ \text { Cataracts } & 714(7.5) \\ \text { Glaucoma } & 406(4.2)\end{array}$


(COPD).

The variations in the clinical parameters of these patients when comparing the baseline measurement with the first measurement after the end of lockdown, and the baseline measurement with the measurement in the following 6 months, can be observed in Table 2. Only the subtle worsening observed in blood creatinine [P 0.043 (95\% CI: 0.26 - 16.31); P 0.043 (95\% CI: 0.25 - 16.06)] and the slight improvement in LDL cholesterol [P 0.037 (95\% CI: -0.06 - -0.00); P 0.027 (95\% CI: -0.06 - -0.00)] presented statistically significant differences. 
Table 2. Changes in the clinical parameters of alcohol abuse disorder patients before lockdown, just after and six months after.

\begin{tabular}{|c|c|c|c|c|c|c|c|c|}
\hline & \multirow[b]{2}{*}{$\mathrm{N}$} & \multirow[t]{2}{*}{$\begin{array}{l}\text { Six months } \\
\text { before }\end{array}$} & \multirow{2}{*}{$\begin{array}{c}\text { 1st measure } \\
\text { post- lockdown } \\
\text { Mean (SD) }\end{array}$} & \multirow[t]{2}{*}{$\begin{array}{l}\text { Six months } \\
\text { after }\end{array}$} & \multicolumn{2}{|c|}{$\begin{array}{c}\text { Difference between pre }-1^{\circ} \\
\text { post }\end{array}$} & \multicolumn{2}{|c|}{$\begin{array}{l}\text { Difference between pre - } \\
\text { follow up }\end{array}$} \\
\hline & & & & & $95 \% \mathrm{CI}$ & $\mathrm{P}$ & $95 \% \mathrm{CI}$ & $\mathrm{P}$ \\
\hline GOT & 87 & $33.5(36.3)$ & $29.8(15.7)$ & $29.7(15.7)$ & $-3.82 ; 11.26$ & 0.330 & $-3.81 ; 11.31$ & 0.327 \\
\hline GPT & 94 & $29.5(30.3)$ & $27.5(17.1)$ & $27.6(17.2)$ & $-4.46 ; 8.40$ & 0.545 & $-4.53 ; 8.31$ & 0.561 \\
\hline Blood creatinine & 110 & $0.9(0.3)$ & $1.0(0.3)$ & $1.0(0.3)$ & $-0.06 ;-0.00$ & 0.037 & $-0.06 ;-0.00$ & 0.027 \\
\hline Glomerular filtration & 110 & $85.9(20.9)$ & $84.3(21.4)$ & $84.1(21.4)$ & $-0.27 ; 3.48$ & 0.092 & $-0.08 ; 3.72$ & 0.060 \\
\hline Systolic blood pressure & 941 & $135.9(15.8)$ & $136.5(18.3)$ & $135.7(16.5)$ & $-1.71 ; 0.52$ & 0.295 & $-0.83 ; 1.16$ & 0.749 \\
\hline Diastolic blood pressure & 941 & $78.0(10.1)$ & $78.2(11.4)$ & $77.9(10.4)$ & $-0.81 ; 0.50$ & 0.633 & $-0.51 ; 0.70$ & 0.752 \\
\hline Total cholesterol & 109 & $204.5(53.4)$ & $198.6(51.1)$ & $198.3(50.3)$ & $-2.95 ; 14.84$ & 0.188 & $-2.56 ; 14.93$ & 0.164 \\
\hline LDL & 92 & $119.9(48.2)$ & $111.6(41.9)$ & $111.7(41.5)$ & $0.26 ; 16.31$ & 0.043 & $0.25 ; 16.06$ & 0.043 \\
\hline HDL & 100 & $55.2(19.4)$ & $54.7(19.1)$ & $54.8(19.0)$ & $-2.10 ; 3.09$ & 0.707 & $-2.16 ; 2.99$ & 0.748 \\
\hline Triglycerides & 102 & $148.3(122.1)$ & $150.8(88.8)$ & $151.2(89.2)$ & $-21.59 ; 16.55$ & 0.793 & $-21.73 ; 15.91$ & 0.760 \\
\hline BMI & 347 & $30.3(5.4)$ & $30.2(5.5)$ & $30.2(5.5)$ & $-0.06 ; 0.26$ & 0.211 & $-0.05 ; 0.27$ & 0.179 \\
\hline
\end{tabular}

Glutamate - oxaloacetate (GOT); Glutamate pyruvate (GPT); Low density lipoprotein (LDL); High density lipoprotein (HDL); Body mass index (BMI); Standard deviation (SD); Confidence interval

Table 3 shows the changes in drug use patterns among the population with this disorder. For all drugs used in the treatment of 1 chronic alcoholism, the total number of DHDs experienced a decrease in the 6 months following the end of lockdown. The same trend 2 is shown in the total number of DHDs of antidepressants, with the exception of Sertraline. In contrast, the total number of DHDs of 3 benzodiazepines (Diazepam, Lorazepam, Alprazolam, Triazolam, Lormetazepam, Midazolam and Loprazolam) is increased com- 4 pared to the 6 months prior to the start of lockdown. 
Table 3. Number of DHDs six months before and six months after lockdown.

Six months before Six months after

$\longrightarrow$

Drugs used in addictive disorders

$\begin{array}{lcc}\text { Varenicline } & 4.22 & 2.87 \\ \text { Disulfiram } & 0.73 & 0.71 \\ \text { Acamprosate } & 0.001 & 0.001 \\ \text { Nalmefene } & 0.46 & 0.44 \\ \text { Naltrexone } & 0.17 & 0.14\end{array}$

Benzodiazepines

\begin{tabular}{lcc}
\hline Anxiolytics & & \\
Diazepam & 13.24 & 13.47 \\
Potassium clorazepate & 2.23 & 2.16 \\
Lorazepam & 61.97 & 68.91 \\
Bromazepam & 0.75 & 0.74 \\
Clobazam & 0.03 & 0.02 \\
Ketazolam & 0.24 & 0.24 \\
Alprazolam & 142.48 & 152.26 \\
Hypnotics and sedatives & & \\
Flurazepam & 0.14 & 0.14 \\
Triazolam & 2.74 & 2.83 \\
Lormetazepam & 209.92 & 215.45 \\
Midazolam & 0.25 & 0.28 \\
Brotizolam & 1.77 & 0.73 \\
Quazepam & 0.01 & 0.01 \\
Loprazolam & 0.74 & 0.78 \\
Antidepressants & & \\
\hline
\end{tabular}


19Non-selective monoamine reuptake inhibitors

\begin{tabular}{|c|c|c|c|}
\hline \multirow{2}{*}{1} & Imipramine & 0.001 & 0.001 \\
\hline & Clomipramine & 0.09 & 0.08 \\
\hline 12 & Amitriptyline & 0.11 & 0.10 \\
\hline \multirow{2}{*}{13} & Nortriptyline & 0.003 & 0.002 \\
\hline & Doxepin & 0.00 & 0.00 \\
\hline 14 & Maprotiline & 0.01 & 0.01 \\
\hline \multicolumn{4}{|c|}{ Selective serotonin reuptake inhibitors } \\
\hline & Fluoxetine & 2.71 & 2.36 \\
\hline 16 & Citalopram & 0.62 & 0.59 \\
\hline \multirow{2}{*}{17} & Paroxetine & 2.81 & 2.80 \\
\hline & Sertraline & 1.37 & 1.41 \\
\hline 18 & Fluvoxamine & 0.01 & 0.01 \\
\hline & Escitalopram & 17.15 & 16.65 \\
\hline
\end{tabular}

Variations in the use of health resources by patients diagnosed with alcohol abuse who did not become infected with COVID-19 can be seen in Table 4. In the 6 months after the end of the lockdown, the number of visits to the nurse at the health center both ordinary [P <0.001 (95\% CI: 0.21 - 0.69)] and continued care [P 0.005 (95\% CI: 0.17 - 0.97)] experienced a statistically significant decrease. In contrast, the number of visits to the general practitioner at the health center for ordinary care $[\mathrm{P}<0.001$ ( $95 \% \mathrm{CI}:-0.53--0.23)]$ and the number of visits to social work services [P 0.013 (95\% CI: -3.14 - -0.39)] showed a statistically significant increase in relation to the 6 months prior to the start of lockdown.

Regarding the performance of diagnostic tests on these patients, the number of X-rays, hemograms, biochemistry, immunological and urine test were reduced. In contrast, the number of resonances and microbiology tests increased $[\mathrm{P}<0.005]$.

The number of visits to hospital care services (number of visits to accident and emergency services and number of hospitalizations) by patients diagnosed with alcohol abuse also shows a decrease, which is only statistically significant for the number of hospitalizations [P <0.001 (95\% CI: 0.88 - 1.04)]. 


\begin{tabular}{l}
\hline No. of nursing visits (ordinary care) at health centre or by telephone \\
No. of nursing visits (ordinary care) at home \\
No. of nursing visits (continuous care) at health centre \\
No. of nursing visits (continuous care) at home \\
No. of general practitioner visits (ordinary care) at health centre or by \\
telephone \\
No. of general practitioner visit (ordinary care) at home \\
No. of general practitioner visits (continuous care) al health centre \\
No. of general practitioner visits (continuous care) at home \\
No. of visits to other professionals \\
Social worker \\
No. of visits to specialised care (first consultation) \\
No. of visits to specialised care (successive consultations) \\
No. of diagnostic test performed \\
X-rays \\
Ultrasound \\
Resonance \\
CT scans \\
Digestive test \\
Hemograms \\
Biochemistry \\
Microbiology \\
Immunology test \\
Coagulation \\
Urine test
\end{tabular}

No. of visits to $A \& E$ department
Six months before Six months after

N
2738
135
261
33
5799

\begin{tabular}{cc}
\hline \multicolumn{2}{c}{ Mean (SD) } \\
\hline $4.72(6.35)$ & $4.27(5.87)$ \\
$6.10(9.99)$ & $6.63(13.37)$ \\
$2.58(3.49)$ & $2.01(2.08)$ \\
$3.06(7.31)$ & $2.67(6.60)$
\end{tabular}

\begin{tabular}{cc}
\hline $95 \% \mathrm{CI}$ & $\mathrm{P}$ \\
\hline $0.21 ; 0.69$ & $<0.001$ \\
$-2.11 ; 1.04$ & 0.505 \\
$0.17 ; 0.97$ & 0.005 \\
$-0.27 ; 1.06$ & 0.235 \\
$-0.53 ;-0.23$ & $<0.001$ \\
$-0.36 ; 1.06$ & 0.325 \\
$-0.31 ; 0.12$ & 0.395 \\
$-0.24 ; 0.71$ & 0.318
\end{tabular}

$\begin{array}{ll}1.23(1.46) & 1.07(1.44) \\ 0.36(0.61) & 0.32(0.55) \\ 0.12(0.36) & 0.15(0.41) \\ 0.46(0.78) & 0.51(0.78) \\ 0.01(0.13) & 0.01(0.15) \\ 0.34(0.56) & 0.28(0.51) \\ 1.04(0.67) & 0.85(0.71) \\ 0.20(0.62) & 0.33(0.74) \\ 0.21(0.45) & 0.15(0.40) \\ 0.03(0.17) & 0.04(0.22) \\ 0.31(0.58) & 0.24(0.55) \\ 2.14(2.51) & 2.01(2.29)\end{array}$

$0.07 ; 0.25$

0.001

$-0.00 ; 0.07 \quad 0.079$

$-0.06 ;-0.00 \quad 0.044$

$-0.09 ; 0.01 \quad 0.101$

$-0.01 ; 0.01 \quad 0.777$

$0.03 ; 0.10 \quad 0.001$

$0.14 ; 0.24<0.001$

$-0.17 ;-0.07<0.001$

$0.02 ; 0.08<0.001$

$-0.02 ; 0.00 \quad 0.123$

$0.03 ; 0.10<0.001$

$-0.04 ; 0.31 \quad 0.138$


Accident and emergency (A\&E); Standard deviation (SD); Confidence interval (CI).

The comparison of the clinical parameters between alcoholic patients infected with COVID-19 and those not infected can be seen 39 in detail in Table 5. Patients infected by COVID-19 presented higher BMI values than those who did not contract the infection. This difference were significant both for the six months prior to the start of lockdown [P 0.010 (95\% CI: -3.07 - -0.42)] and for the six months after its completion [P 0.001 (95\% CI: -6.02 - 1.52)]. For the rest of the variables, no statistically significant differences were found

Table 5. Changes in the clinical parameters of alcoholic patients with COVID - 19 and without COVID - 19 before lockdown and six months after.

\section{9} 40

\begin{tabular}{|c|c|c|c|c|c|c|c|c|c|c|c|c|}
\hline & \multicolumn{6}{|c|}{ Six months before } & \multicolumn{6}{|c|}{ Six months after } \\
\hline & \multicolumn{2}{|c|}{ With COVID } & \multicolumn{2}{|c|}{ Without COVID } & \multirow[b]{2}{*}{$95 \% \mathrm{CI}$} & \multirow[b]{2}{*}{$\mathrm{P}$} & \multicolumn{2}{|c|}{ With COVID } & \multicolumn{2}{|c|}{ Without COVID } & \multirow[b]{2}{*}{$95 \% \mathrm{CI}$} & \multirow[b]{2}{*}{$\mathrm{P}$} \\
\hline & $\mathrm{N}$ & Mean (SD) & $\mathrm{N}$ & Mean (SD) & & & $\mathrm{N}$ & Mean (SD) & $\mathrm{N}$ & Mean (SD) & & \\
\hline GOT & 32 & $30.3(11.9)$ & 615 & $34.8(36.9)$ & $-8.31 ; 17.39$ & 0.488 & 35 & $35.5(23.6)$ & 460 & $38.0(48.5)$ & $-13.75 ; 18.78$ & 0.761 \\
\hline GPT & 35 & $34.5(26.2)$ & 656 & $33.0(28.5)$ & $-11.19 ; 8.16$ & 0.758 & 36 & $38.6(41.9)$ & 496 & $35.4(41.0)$ & $-17.09 ; 10.75$ & 0.655 \\
\hline Glomerular filtration & 37 & $91.9(18.1)$ & 700 & $90.1(18.0)$ & $-7.75 ; 4.19$ & 0.558 & 36 & $88.6(17.2)$ & 544 & $86.7(20.0)$ & $-8.67 ; 4.71$ & 0.562 \\
\hline SBP & 128 & $135.1(17.7)$ & 2519 & 135.5 (16.7) & $-2.52 ; 3.44$ & 0.761 & 60 & $134.3(20.7)$ & 1343 & $135.7(17.1)$ & $-3.09 ; 5.86$ & 0.543 \\
\hline DBP & 128 & $78.3(10.9)$ & 2515 & $79.6(10.8)$ & $-0.55 ; 3.28$ & 0.162 & 60 & $77.4(13.9)$ & 1343 & $79.2(11.2)$ & $-1.09 ; 4.75$ & 0.220 \\
\hline BMI & 70 & $31.5(6.0)$ & 1277 & $29.7(5.4)$ & $-3.07 ;-0.42$ & 0.010 & 24 & $33.6(6.1)$ & 585 & $29.8(5.5)$ & $-6.02 ; 1.52$ & 0.001 \\
\hline
\end{tabular}

Glutamate - oxaloacetate (GOT); Glutamate pyruvate (GPT); Systolic blood pressure (SBP); Diastolic blood pressure (DBP); Body mass index (BMI); Standard deviation (SD); Confidence interval (CI). 


\section{Discussion}

The results of our study do not show clinically relevant changes in the biological markers of this disease; which would suggest the stable maintenance of alcohol consumption during the months of lockdown.

Other studies published in the population with alcohol use disorder also contradict the hypothesis of an increase in consumption during the health crisis, when showing this maintenance [36] or even a decrease in the consumption $[37,38]$ of this substance after the start of the sanitary measures established to stop the spread of the virus. However, some studies have reported an increase in alcohol consumption [24] and in the number of relapses during the months of lockdown $[39,40]$; having a higher risk of quitting abstinence those who experienced emotional distress, or lived alone at the onset of the pandemic [41]. However, the vast majority of these studies have investigated the impact of lockdown on alcohol consumption patterns through online questionnaires in small samples, not evaluating biological markers [36,37,39].

The maintenance of clinical parameters observed in our study could in part be explained by the continuous provision of care to these patients during and after lockdown. Some foundations in our community, such as the Zaragoza Solidarity Center - Proyecto Hombre (CSZ - PH), were recognized by the Ministry of Health of the Government of Aragon as essential services. This recognition allowed these services to remain open at all times, providing telematic or even face-to-face care to all patients and their families [42]. The same situation is found in other Spanish regions, where the maintenance of basic care for patients with alcohol use disorder seems to have cushioned the impact of COVID-19, by promoting abstinence and therefore protecting against possible relapses [43].

Regarding the variations in the consumption of drugs in the six months after the end of the lockdown, there are no notable differences in the total number of DHDs dispensed in the pharmacy in the drugs used for the treatment of dependencies, nor in the antidepressants. These slight variations would once again highlight the adequate management during the COVID-19 pandemic of the patient with alcohol abuse disorder [43] through telephonic consultations. On the other hand, the high rates of irritability, anxiety or somatization that several studies have reported [36,41] among this population during the months of lockdown, could be behind the increase in the number of DHDs of some benzodiazepines (Diazepam, Lorazepam, Alprazolam , Triazolam, Lormetazepam, Midazolam and Loprazolam).

The use of resources from the National Health System by patients with alcohol abuse disorder experienced a decrease compared to the six months prior to the start of lockdown. These results are in line with those published by the WHO in the survey on the impact of the pandemic on mental, neurological and substance use services [44], where 93\% of the surveyed countries declared interruptions in these services. Telemedicine has been consolidated as one of the most frequent and effective alternatives to overcome these interruptions [43-45], and could explain the increase in the number of ordinary face-toface or telephone visits to the general practitioner observed in our work. The increase, according to various reports published in our country [46,47], in the demand for Social Services in the months after the pandemic, could explain the notable increase in the number of consultations to social work services.

Patients with substance abuse disorder usually present physical and mental comorbidities $[28,29]$, which have been considered by some studies $[48,49]$ as risk factors of greater severity of the infection. The results of our work reflect a higher prevalence of obesity among patients with alcohol abuse disorder infected by COVID-19, which could contribute to a worse prognosis and evolution of the disease.

Regarding the excess of mortality observed in the six months after the end of lockdown, the emotional distress experienced [36,41] by this group during the pandemic months together with the consequent economic crisis generated by COVID-19, could have increased mortality and the number of suicides [50]. Previous studies [51] have placed 
alcohol dependence among the diagnostic groups with the highest risk of suicide, behind depression and schizophrenia.

Our study has several limitations. First of all, we do not have access to a quantified record of alcohol consumption in Standard Drinking Units, nor to some of the specific structured questionnaires used in PC such as the CAGE or the Alcohol Use Disorders Identification Test (AUDIT). Second, although our study includes men over 16 years of age with a diagnosis of alcohol abuse in their EMR, we do not know the phase in which they are (detoxification, cessation or rehabilitation). Finally, the number of records for each of the clinical variables included in this study was very limited. Access to these data depends on their validation by the general practitioner, so that we only had access to the data that were validated by the doctor. The exclusive use of the EMR also prevented the collection of self-reported data on the lifestyles maintained during the months of the pandemic.

\section{Conclusions}

Our study contributes to the knowledge from a longitudinal perspective of the consequences of the COVID-19 pandemic in the clinical, pharmacological and health resources use parameters of a large sample of men diagnosed with alcohol abuse disorder.

Although unforeseen, the results of our study suggest that the impact of COVID-19 among this group has been moderate. The reorganization of health and social services after the declaration of the state of alarm in our country, made it possible to maintain care for this vulnerable group.

Author Contributions: Conceptualization, B.O.-B.; formal analysis, S.C.-V., A.C., B.O.-B., and A.L.C.; writing-original draft preparation, A.L.-C.; writing-review and editing, B.G.A, B.O.-B., A.C., and S.C.-V; supervision, B.O.-B. All authors have read and agreed to the published version of the manuscript.

Funding: This study has been funded by the Department for Science, Universities and the Knowledge Society of the Government of Aragon (Spain), through the DGACovid-01 project.

Informed Consent Statement: This report does not contain patient identifiable data. Consent from individuals involved in this study was not required.

Data Availability Statement: Requests for any underlying data cannot be granted by the authors because the data was acquired under a license/data sharing agreement with the Aragon Health Services, under which conditions of use (and further use) apply.

Acknowledgments: We should like to thank: the Preventive Activity \& Health Promotion Research Network (Red de Prevención y Promoción de la Salud en Atención Primaria/RedIAPP), Carlos III Institute of Health, Spain); the B21_20R Research Group of the Department of Research, Innovation and Universities of the Aragon Regional Authority (Spain); and the European Regional Development Fund (FEDER) "Otra forma de hacer Europa".

Conflicts of Interest: The authors declare no conflict of interest.

101

4. Gobierno de España. Ministerio de la Presidencia. Real Decreto 463/2020. Boletín Oficial del Estado [Internet]. 2020 p. 25390400. Available from: https://www.boe.es/boe/dias/2020/03/14/pdfs/BOE-A-2020-3692.pdf 
5. Ramírez-Ortiz J, Castro-Quintero D, Lerma-Córdoba C, Yela-Ceballos F, Escobar-Córdoba F. Mental health consequences of the COVID-19 pandemic associated with social isolation. Colombian Journal of Anesthesiology. 2020;48(4):e930. doi: https://doi.org/10.5554/22562087.e930

6. Huang Y, Zhao N. Generalized anxiety disorder, depressive symptoms and sleep quality during COVID-19 outbreak in China: a web-based cross-sectional survey. Psychiatry Res. 2020;288:112954. doi:10.1016/j.psychres.2020.112954

7. Jungmann SM, Witthöft M. Health anxiety, cyberchondria, and coping in the current COVID-19 pandemic: Which factors are related to coronavirus anxiety? J Anxiety Disord. 2020;73:102239. doi:10.1016/j.janxdis.2020.102239

8. Moghanibashi-mansourieh A. Assessing the anxiety level of Iranian general population during COVID-19 outbreak. Asian J Psychiatr. 2020;51:102076. doi:10.1016/j.ajp.2020.102076

9. Qiu J, Shen B, Zhao M, Wang Z, Xie B, Xu Y. A nationwide survey of psychological distress among Chinese people in the COVID-19 epidemic: Implications and policy recommendations. Gen Psychiatry. 2020;33(2):e100213. doi:10.1136/gpsych-2020100213

10. García-Álvarez L, de la Fuente-Tomás L, García-Portilla MP, Sáiz PA, Lacasa CM, Santo FD, et al. Early psychological impact of the 2019 Coronavirus disease (COVID-19) pandemic and lockdown in a large Spanish sample. J Glob Health. 2020;10(2):115. doi:10.7189/jogh.10.020505

11. Wang C, Pan R, Wan X, Tan Y, Xu L, Ho CS, et al. Inmediate Psychological Responses and Associated Factors during the Initial Stage of the 2019 Coronavirus Disease (COVID-19) Epidemic among the General Population in China. Int J Environ Res Public Health. 2020;17(5):1729. doi:10.3390/ijerph17051729

12. Villanueva VJ, Motos $\mathrm{P}$, Isorna M, Villanueva V, Blay P, Vázquez-Martínez A. Impacto de las medidas de confinamiento durante la pandemia de Covid-19 en el consumo de riesgo de alcohol. Rev Esp Salud Pública. 2021; 95:1-13.

13. Organización Mundial de la Salud. El consumo nocivo de alcohol mata a más de 3 millones de personas al año, en su mayoría hombres [Internet]. 2018 [cited 2021 October 24]. Available from: https://www.who.int/es/news/item/21-09-2018-harmful-useof-alcohol-kills-more-than-3-million-people-each-year--most-of-them-men

14. GBD 2016 Alcohol Collaborators. Alcohol use and burden for 195 countries and territories, 1990-2016: a systematic analysis for the Global Burden of Disease Study 2016. Lancet. 2018:392(10152):1015-35. doi: 10.1016/S0140-6736(18)31310-2

15. Sociedad Científica Española de Estudios sobre el Alcohol, el Alcoholismo y las otras Toxicomanías. Manual de consenso sobre alcohol en Atención Primaria [Internet]. 2016 [cited 2021 October 24]. Available from: https://pnsd.sanidad.gob.es/profesionales/publicaciones/catalogo/bibliotecaDigital/publicaciones/pdf/16 Socimanualconsensoalcoholatprimaria2016.pdf

16. Guignard R, Andler R, Quatremère G, Pasquereau A, du Roscoät E, Arwidson P, et al. Changes in smoking and alcohol consumption during COVID-19-related lockdown: A cross-sectional study in France. Eur J Public Health. 2021;1-8. doi: 10.1093/eurpub/ckab054

17. Sidor A, Rzymski P. Dietary choices and habits during COVID-19 lockdown: Experience from Poland. Nutrients. 2020;12(6):113. doi:10.3390/nu12061657

18. Schmits E, Glowacz F. Changes in Alcohol Use During the COVID-19 Pandemic: Impact of the Lockdown Conditions and Mental Health Factors. Int J Ment Health Addict. 2021;1-12. doi:10.1007/s11469-020-00432-8

19. Koopmann A, Georgiadou E, Kiefer F, Hillemacher T. Did the General Population in Germany Drink More Alcohol during the COVID-19 Pandemic Lockdown? Alcohol Alcohol. 2020;55(6):698-9. doi:10.1093/alcalc/agaa058

20. Jacob L, Smith L, Armstrong NC, Yakkundi A, Barnett Y, Butler L, et al. Alcohol use and mental health during COVID-19 lockdown: A cross-sectional study in a sample of UK adults. Drug Alcohol Depend. 2021;219:108488. doi:10.1016/j.drugalcdep.2020.108488

21. Stanton R, To QG, Khalesi S, Williams SL, Alley SJ, Thwaite TL, et al. Depression, anxiety and stress during COVID-19: Associations with changes in physical activity, sleep, tobacco and alcohol use in Australian adults. Int J Environ Res Public Health. 2020;17(11):1-13. doi:10.3390/ijerph17114065

22. Da BL, Im GY, Schiano TD. Coronavirus Disease 2019 Hangover: A Rising Tide of Alcohol Use Disorder and Alcohol-Associated Liver Disease. Hepatology. 2020;72(3):1102-8. doi:10.1002/hep.31307

23. Pascale A. Consumo de sustancias psicoactivas durante la pandemia por COVID-19: implicancias toxicológicas desde un enfoque integral y desafíos terapéuticos. Rev méd Urug. 2020;36(3):333-4.

24. Barrio P, Baldaquí N, Andreu M, Kilian C, Rehm J, Gual A, et al. Abstinence Among Alcohol Use Disorder Patients During the COVID-19 Pandemic: Insights From Spain. Alcohol Clin Exp Res. 2021;45(4):802-7. doi:10.1111/acer.14555

25. Testino G. Are Patients with Alcohol Use Disorders at Increased Risk for Covid-19 Infection. Alcohol Alcohol. 2020;55(4):3446. doi:10.1093/alcalc/agaa037

26. Drobes DJ. Concurrent alcohol and tobacco dependence mechanisms and treatment. Alcohol Res Heal. 2002;26(2):136-42.

27. Saha TD, Grant BF, Chou SP, Kerridge BT, Pickering RP, Ruan WJ. Concurrent use of alcohol with other drugs and DSM-5 alcohol use disorder comorbid with other drug use disorders: Sociodemographic characteristics, severity, and psychopathology. Drug Alcohol Depend. 2018;187:261-9. doi:10.1016/j.drugalcdep.2018.03.006

28. Parry CD, Patra J, Rehm J. Alcohol consumption and non-communicable diseases: Epidemiology and policy implications. Addiction. 2011;106(10):1718-24. doi:10.1111/j.1360-0443.2011.03605.x

29. Klimkiewicz A, Klimkiewicz J, Jakubczyk A, Kieres-Salomoński I, Wojnar M. Comorbidity of alcohol dependence with other psychiatric disorders. Part I - Epidemiology of dual diagnosis. Psychiatr Pol. 2015;49(2):265-75. doi:10.12740/PP/25704

30. Benzano D, Ornell F, Schuch JB, Pechansky F, Sordi AO, von Diemen L, et al. Clinical vulnerability for severity and mortality by COVID-19 among users of alcohol and other substances. Psychiatry Res. 2021;300:113915. doi:10.1016/j.psychres.2021.113915 
31. Comité Internacional de Clasificación de la WONCA. Clasificación Internacional de la Atención Primaria (CIAP-2). 2º . Masson, editor. Barcelona; 1999.

32. Organización Panamericana de la Salud. Alcohol y atención primaria de la salud. Informaciones clínicas básicas para la identificación y el manejo de riesgos y problemas [Internet]. 2008 [cited 2021 December 1]. Available from: https://www.who.int/substance abuse/publications/alcohol atencion primaria.pdf

33. Calderón-Larrañaga A, Vetrano DL, Onder G, Gimeno-Feliu LA, Coscollar-Santaliestra C, Carfí A, et al. Assessing and Measuring Chronic Multimorbidity in the Older Population: A Proposal for Its Operationalization. J Gerontol A Biol Sci Med Sci. 2017;72(10):1417-23. doi:10.1093/gerona/glw233

34. Sociedad Española de Medicina de Familia y Comunitaria. Guía de referencia rápida para abordar el abuso de alcohol [Internet]. 2005 [cited 2021 December 1]. Available from: https://www.semfyc.es/wp-content/uploads/2016/07/abuso-alcohol.pdf

35. Lubin Pigouche P, Maciá Antón MA, Rubio de Lemus P. Mathematical Psychology. Madrid: Universidad Nacional de Educación a Distanica;2005.

36. Blithikioti C, Nuño L, Paniello B, Gual A, Miquel L. Impact of COVID-19 lockdown on individuals under treatment for substance use disorders: Risk factors for adverse mental health outcomes. J Psychiatr Res. 2021;139:47-53. doi: 10.1016/j.jpsychires.2021.05.006.

37. Pabst A, Bollen Z, Creupelandt C, Fontesse S, Maurage P. Alcohol consumption changes following COVID-19 lockdown among French-speaking Belgian individuals at risk for alcohol use disorder. Prog Neuropsychopharmacol Biol Psychiatry. 2021;110:110282. doi: 10.1016/j.pnpbp.2021.110282.

38. Jackson SE, Garnett C, Shahab L, Oldham M, Brown J. Association of the COVID-19 lockdown with smoking, drinking and attempts to quit in England: an analysis of 2019-20 data. Addiction. 2021;116(5):1233-44. doi: 10.1111/add.15295.

39. Kim JU, Majid A, Judge R, Crook P, Nathwani R, Selvapatt N, et al. Effect of COVID-19 lockdown on alcohol consumption in patients with pre-existing alcohol use disorder. Lancet Gastroenterol Hepatol. 2020;5(10):886-7. doi: 10.1016/S2468$\underline{1253(20) 30251-X .}$

40. Sun Y, Li Y, Bao Y, Meng S, Sun Y, Schumann G, et al. Brief report: increased addictive internet and substance use behaviour during the COVID- 19 pandemic in China. Am J Addict. (2020) 29:268-70. https://doi.org/10.1111/ajad.13066

41. Yazdi K, Fuchs-Leitner I, Rosenleitner J, Gerstgrasser NW. Impact of the COVID-19 Pandemic on Patients With Alcohol Use Disorder and Associated Risk Factors for Relapse. Front Psychiatry. 2020;11:620612. doi: 10.3389/fpsyt.2020.620612.

42. Fundación CSZ Proyecto Hombre. Memoria 2020 CSZ - Proyecto hombre [Internet]. 2021 [Cited 2021 November 11]. Available from: http://www.fundacioncsz.org/ArchivosPublicaciones/328.pdf

43. Roncero C, Vicente-Hernández B, Casado-Espada NM, Aguilar L, Gamonal-Limcaoco S, Garzón MA, et al. The Impact of COVID-19 Pandemic on the Castile and Leon Addiction Treatment Network: A Real-Word Experience. Front Psychiatry. 2020;11:575755. doi: 10.3389/fpsyt.2020.575755.

44. World Health Organization. The impact of COVID - 19 on mental, neurological and substance use services [Internet]. 2020 [Cited 2021 November 11]. Available from: https://www.who.int/publications/i/item/978924012455

45. Tofighi B, Abrantes A, Stein MD. The Role of Technology-Based Interventions for Substance Use Disorders in Primary Care: A Review of the Literature. Med Clin North Am. 2018 Jul;102(4):715-31. doi: 10.1016/j.mcna.2018.02.011.

46. Instituto Nacional de Administración Pública. Los servicios sociales ante la pandemia: más demandas que atender y más retos ante la complejidad [Internet]. 2020 [Cited 2021 November 11]. Available from: https://www.seaus.net/images/stories/pdf/serviciossocialespandemia.pdf

47. Instituto Nacional de Administración Pública. Los servicios sociales ante la pandemia: retos, desafíos y respuestas hacia la nueva normalidad [Internet]. 2020 [Cited 2021 November 11]. Available from: https://www.inap.es/documents/84257/0/INFORME+MONITOR+DE+IMPACTO-SEPTIEMBRE.pdf

48. Richardson S, Hirsch JS, Narasimhan M, Crawford JM, McGinn T, Davidson KW et al. Presenting Characteristics, Comorbidities, and Outcomes Among 5700 Patients Hospitalized With COVID-19 in the New York City Area. JAMA. 2020;323(20):205259. doi: $10.1001 /$ jama.2020.6775.

49. Zhou F, Yu T, Du R, Fan G, Liu Y, Liu Z, et al. Clinical course and risk factors for mortality of adult inpatients with COVID-19 in Wuhan, China: a retrospective cohort study. Lancet. 2020;395(10229):1054-62. doi: 10.1016/S0140-6736(20)30566-3.

50. Eliason M. Alcohol-related morbidity and mortality following involuntary job loss: evidence from Swedish register data. J Stud Alcohol Drugs. 2014;75(1):35-46. doi: 10.15288/jsad.2014.75.35.

51. Aparicio D. Trastornos mentales en el mundo. Gráficos con datos sobre la prevalencia de los trastornos mentales según género, edad y país [Internet]. 2019 [Update January 2019; cited November 2021]. Available from: https://www.psyciencia.com/trastornos-mentales-en-el-mundo-graficos/ 